\title{
Dehydrogenation of Cyclohexanol to Cyclohexanone Over Nitrogen-doped Graphene supported $\mathrm{Cu}$ catalyst
}

\author{
Alyaa K. Mageed1,*, Dayang A.B. Radiah ${ }^{2}$, A. Salmiaton ${ }^{2}$, Shamsul Izhar ${ }^{2}$, \\ Musab Abdul Razak ${ }^{2}$, Bamidele Victor Ayodele ${ }^{3, *}$ \\ ${ }^{1}$ Department of Chemical Engineering, University of Technology, Baghdad, Iraq. \\ ${ }^{2}$ Department of Chemical and Environmental Engineering, Faculty of Engineering, Universiti Putra \\ Malaysia, 43400, Serdang, Selangor, Malaysia. \\ 3Institute of Energy Policy and Research, Universiti Tenaga Nasional, Jalan IKRAM-UNITEN 43000, \\ Kajang, Selangor, Malaysia.
}

Received: $16^{\text {th }}$ December 2019; Revised: $9^{\text {th }}$ July 2020; Accepted: $9^{\text {th }}$ July 2020; Available online: 30th July 2020; Published regularly: August 2020

\begin{abstract}
In this study, the dehydrogenation of cyclohexanol to cyclohexanone over nitrogen-doped reduced graphene oxide (N-rGO) Cu catalyst has been reported. The N-rGO support was synthesized by chemical reduction of graphite oxide (GO). The synthesized $\mathrm{N}$-rGO was used as a support to prepare the $\mathrm{Cu} / \mathrm{N}$ rGO catalyst via an incipient wet impregnation method. The as-prepared support and the $\mathrm{Cu} / \mathrm{N}-\mathrm{rGO}$ catalyst were characterized by FESEM, EDX, XRD, TEM, TGA, and Raman spectroscopy. The various characterization analysis revealed the suitability of the $\mathrm{Cu} / \mathrm{N}-\mathrm{rGO}$ as a heterogeneous catalyst that can be employed for the dehydrogenation of cyclohexanol to cyclohexanone. The catalytic activity of the $\mathrm{Cu} / \mathrm{N}$-rGO catalyst was tested in non-oxidative dehydrogenation of cyclohexanol to cyclohexanone using a stainless-steel fixed bed reactor. The effects of temperature, reactant flow rate, and time-onstream on the activity of the $\mathrm{Cu} / \mathrm{N}-\mathrm{rGO}$ catalyst were examined. The $\mathrm{Cu} / \mathrm{N}-\mathrm{rGO}$ nanosheets show excellent catalytic activity and selectivity to cyclohexanone. The formation of stable $\mathrm{Cu}$ nanoparticles on $\mathrm{N}$ rGO support interaction and segregation of $\mathrm{Cu}$ were crucial factors for the catalytic activity. The highest cyclohexanol conversion and selectivity of $93.3 \%$ and $82.7 \%$, respectively, were obtained at a reaction temperature of $270{ }^{\circ} \mathrm{C}$ and cyclohexanol feed rate of $0.1 \mathrm{ml} / \mathrm{min}$. Copyright $(\mathrm{C} 2020 \mathrm{BCREC}$ Group. All rights reserved
\end{abstract}

Keywords: Cyclohexanol; Cyclohexanone; Copper; dehydrogenation; Nitrogen-doped reduced graphene oxide

How to Cite: Mageed, A.K., Radiah, D.A.B., Salmiaton, A., Izhar, S., Razak, M.A., Ayodele, B.V. (2020). Dehydrogenation of Cyclohexanol to Cyclohexanone Over Nitrogen-doped Graphene supported $\mathrm{Cu}$ catalyst. Bulletin of Chemical Reaction Engineering \& Catalysis, 15(2), 568-578 (doi:10.9767/bcrec.15.2.6774.568-578)

Permalink/DOI: https://doi.org/10.9767/bcrec.15.2.6774.568-578

\section{Introduction}

The dehydrogenation of cyclohexanol to cyclohexanone is an important reaction for the

* Corresponding Author.

E-mail: 80077@uotechnology.edu.iq (A.K. Mageed); ayodelebv@gmail.com (B.V. Ayodele) production of chemical intermediates used for the synthesis of caprolactam, nylon and, polyamide [1]. The industrial-scale cyclohexanone production has been made possible using $\mathrm{Cu}-\mathrm{Mg}$ and $\mathrm{Cu}-\mathrm{Zn}-\mathrm{Al}$ catalysts [2]. The dehydrogenation of cyclohexanol over these catalysts were reported to give conversions ranged $50-60 \%$ and 
cyclohexanone selectivity of 99\% [3]. However, cyclohexanol dehydrogenation has been limited by the reversibility phenomenon of the dehydrogenation reaction which has been reported to keep the cyclohexanol conversion to $50-60 \%$ at $250{ }^{\circ} \mathrm{C}$ [3]. To overcome this limitation, $\mathrm{Cu}$ based catalysts have been investigated for dehydrogenation of cyclohexanol to cyclohexanone $[4,5]$. Attempt in improving the cyclohexanol conversion using these catalysts resulted in a decrease in the selectivity of cyclohexanone due to an increase in the formation of impurities such as phenol and cyclohexene as by-products [6].

The use of support for the synthesis of $\mathrm{Cu}$ catalyst has been shown to improve cyclohexanol conversion and cyclohexanone selectivity [7]. This was due to the efficient dispersion of the $\mathrm{Cu}$ on the support. Simon et al. [4] reported that $\mathrm{ZnO}$ and $\mathrm{MgO}$ supported $\mathrm{Cu}$ catalysts with high loading were found to have high conversion and selectivity, thereby overcoming the limitations in the cyclohexanone production process [4]. Graphene, a two-dimensional carbon nanostructure has many excellent properties such as outstanding charge carrier mobility, thermal and chemical stability, high specific surface area, and superior stability $[8,9]$ could be appropriate support material for the dispersion of $\mathrm{Cu}$. Hence, the dispersion of $\mathrm{Cu}$ on the surface of reduced graphene oxide could form the basis for the development of new catalytic material for dehydrogenation of cyclohexanol. To the best of the author's knowledge, there is no reported work on the dehydrogenation of cyclohexanol over nitrogen-modified RGO supported $\mathrm{Cu}$ catalysts. The modification of the RGO with nitrogen to give N-rGO is expected to enhance the $\mathrm{Cu}$-based catalytic activity and stability $[10,11]$.

The present study, therefore, focuses on the synthesis of $\mathrm{N}-\mathrm{rGO}$ nanosheets supported $\mathrm{Cu}$ catalyst which was prepared as a form of paper, whereas most of the catalytic studies are available as powder forms. The paper-like form of catalysts presents an opportunity ease of handling during an industrial application compared to the powdery form. Besides, the exceptional porous nature of the paper-like catalyst could significantly influence the catalytic activities. Therefore, in this work, the catalyst was prepared in a new paper form and the catalyst performance was evaluated in terms of activities and stability of the synthesized catalyst during catalytic gas-phase dehydrogenation reaction of cyclohexanol to cyclohexanone at the moderate temperatures.

\section{Materials and Methods}

\subsection{Chemicals}

The chemical used in this study were purchased from different manufacturers at various purity grades: Purified graphite powder, concentrated $\mathrm{H}_{2} \mathrm{SO}_{4}$, (MW $=98.07$ g.mole ${ }^{-1}, 98 \%$, Sigma-Aldrich), concentrated $\mathrm{HNO}_{3}$, (MW = 63.01 g.mole ${ }^{-1}, 65 \%$, Fisher Scientific) and $\mathrm{KClO}_{3}$, (MW = 122.5495 g.mole ${ }^{-1}, 99 \%$, Fisher Scientific), $\mathrm{NH}_{3}$ solution (MW $=17.03$ g. $\mathrm{mole}^{-1}$, $30 \%$, Analytical grade - Sigma-Aldrich), were used for the synthesis of the reduced graphene oxide. Copper nitrate trihydrate $(\mathrm{Cu}$ $\left.\left(\mathrm{NO}_{3}\right)_{2} \cdot 3 \mathrm{H}_{2} \mathrm{O}\right) ; \mathrm{MW}=241.60$ g. $\mathrm{mole}^{-1}$, SigmaAldrich) was used as the $\mathrm{Cu}$ precursor. Cyclohexanol (MW $=100.16$ g. $\mathrm{mole}^{-1}, 99.5 \%$, SigmaAldrich) was used as the reactant chemical and standard. Cyclohexanone (MW $=98.15$ g.mole ${ }^{-1}, 99.5 \%$, Sigma-Aldrich) was also used as standard.

\subsection{Preparation of Catalysts}

Before the preparation of the catalyst, the N-rGO support was synthesized by chemical reduction of GO in $\mathrm{NH}_{3}$ environment followed by thermal treatment with $\mathrm{N}_{2}$. The $\mathrm{Cu} / \mathrm{N}$-rGO was prepared by incipient wet impregnation. The support (GO) was prepared from natural graphite flakes using modified Staudenmaier's method as reported by Lee and Seo [12]. For the preparation of the GO, an ice-cooled 2:1 mixture of $\mathrm{H}_{2} \mathrm{SO}_{4}$ and $\mathrm{HNO}_{3}$ was mixed with a stipulated amount of natural flake graphite. The mixture was allowed to react with temperature-controlled at $30{ }^{\circ} \mathrm{C}$ with the addition of $\mathrm{KCLO}_{3}$. Stipulated amount of deionized water was added to the mixture after $96 \mathrm{~h}$ and the mixture was filtered using a nylon membrane to obtain a precipitated GO. The GO was subsequently washed with $\mathrm{HCl}$ solution for removal of sulfite ions impurities and thereafter washed with deionized water to remove any form of chloride ions. The resulting graphite oxide was then exfoliated and reduced to graphene oxide by mixing with $\mathrm{NH}_{3}$ solution for 1 $\mathrm{h}$ and thereafter refluxed at $130{ }^{\circ} \mathrm{C}$ for $3 \mathrm{~h}$. The resulting rGO was subsequently calcined at $200{ }^{\circ} \mathrm{C}$ in the $\mathrm{N}_{2}$ environment for 40 minutes to obtain nitrogen-doped reduced graphene oxide (N-rGO). The thermal method was based on that described by Ning et al. [13].

The $\mathrm{Cu} / \mathrm{N}-\mathrm{rGO}$ catalyst was synthesized using incipient wetness impregnation of the $\mathrm{Cu}$ precursor into the N-rGO support. The mass of the impregnated precursor was calculated to obtain an equivalent amount of $1 \mathrm{wt} \%$ of $\mathrm{Cu}$. 
The wet slurry containing the Cu-precursor and the N-rGO support was dried overnight at $110{ }^{\circ} \mathrm{C}$, calcined, and subsequently reduced in the $\mathrm{N}_{2} / \mathrm{H}_{2}(10 \%(\mathrm{v} / \mathrm{v}))$ environment at $275{ }^{\circ} \mathrm{C}$ for $3 \mathrm{~h}$ to obtain as-synthesized $1 \mathrm{wt} \% \mathrm{Cu} / \mathrm{N}-\mathrm{RGO}$ catalyst.

\subsection{Characterization of Catalysts}

Field emission scanning electron microscopy (FESEM, JSM-7600 F) and transmission electron microscopy (TEM, Hitachi, H-7100) were used for the morphological analyses of the supports (GO, N-rGO) and the $\mathrm{Cu} / \mathrm{N}-\mathrm{rGO}$ catalyst. Prior to the TEM analysis, the catalyst sample was sonicated in absolute ethanol, dried at room temperature $\left(25^{\circ} \mathrm{C}\right)$, and then placed on a carbon-coated copper grid. The elemental composition of the sample was analyzed by energydispersive X-ray spectroscopy (EDX) (JSM-7600 F). A programmed thermal stability test of the catalyst sample was examined under a nitrogen atmosphere using thermogravimetric analysis (TGA) (TA instrument, Q50). To quantify the defects in the product materials, Raman spectra were measured using an excitation wavelength of $532.027 \mathrm{~nm}$ provided by a Spectra Model Alpha 300R and brand WI Tec. The Xray diffraction (XRD) of the catalysts was measured to determine its crystallinity. Using a $2 \theta$ scanning range of $3^{\circ}$ to $180^{\circ}$, the diffractogram was recorded by RIGAKU miniflex II equipped with the latest version of PDXL, RIGAKU full function powder-diffraction analysis software having $\mathrm{Cu} \mathrm{K} \alpha \mathrm{X}$-ray source and wavelength $(\lambda)$ of $0.154 \mathrm{~nm}$.

\subsection{Catalytic Activity}

The reaction study showing the catalytic activity of the $\mathrm{Cu} / \mathrm{N}$-rGO catalyst in the dehydro-

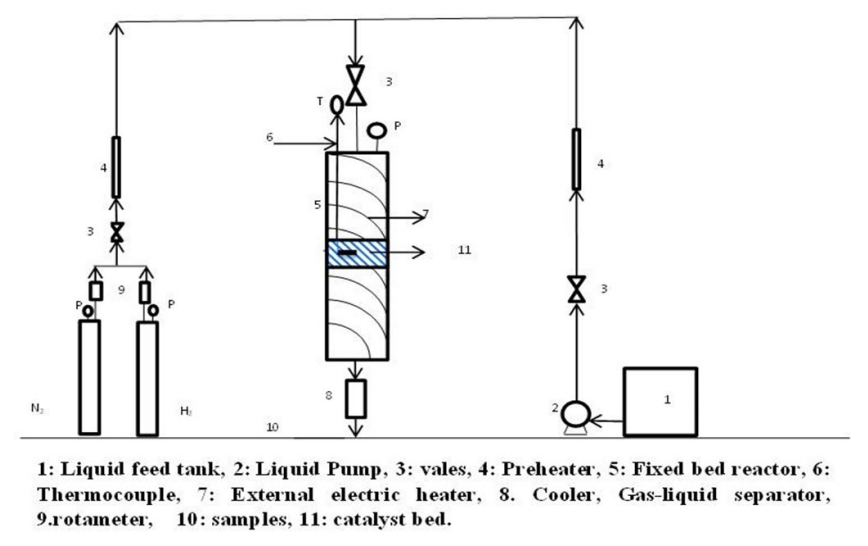

Figure 1. Diagram showing the experimental setup. genation of cyclohexanol to cyclohexanone was performed in a continuous flow fixed bed reactor. The reaction was performed at atmospheric pressure (1 atm). The schematic representation of the experimental setup is depicted in Figure 1. The fixed bed reactor was connected to a nitrogen gas cylinder which serves as the carrier gas and to a liquid micropump for the feeding of the cyclohexanol into the reactor. Approximately $100 \mathrm{mg}$ of the prepared catalyst was loaded into the fixed bed reactor. The reactor which is a stainless steel tube was vertically placed in a furnace heated by an external electric heater and insulated with glass wool. The temperature of the catalytic bed was monitored using a K-type thermocouple. The dehydrogenation process was performed at a temperature range of $200-270{ }^{\circ} \mathrm{C}$, weight hour space velocity (WHSV) of 57 and $114 \mathrm{~h}^{-1}$, and gas hourly space velocity (GHSV) of $1580 \mathrm{~h}^{-1}$. The WHSV was calculated as the weight of feed flow per unit weight of the catalyst per hour while the GHSV was calculated as the hourly volumetric feed gas flow rate/reaction volume. The vapor effluent from the reactor was cooled down to $25^{\circ} \mathrm{C}$ to enhance the separation of the gas and liquid products. The liquid and gas products were collected at node 10 (Figure 1). The liquid products were analyzed using GC/FID (CP-Sil 24 CB $30 \mathrm{~m} \times 0.25 \mathrm{~mm} \times$ $0.25 \mathrm{um})$.

\section{Results and Discussion}

\subsection{Morphology Analysis}

The representative FESEM and TEM analysis showing the morphology of the $\mathrm{Cu} / \mathrm{N}-\mathrm{rGO}$ catalyst are depicted in Figures 2 and 3 respectively. Interestingly, the GO obtained from the acid oxidation was formed by a few layers of GO as shown in Figure 2. A similar observation was also reported by Loryuenyong et al. [14]. It can be seen from the FESEM micrographs that the formed N-rGO nanosheets have distinctive corrugated features. However, this corrugated feature was subsequently transformed into a wavy shape with extended sheets of lateral dimensions ranging from a few micrometers to tens of micrometers in length with layered structures. The effects of doping the GO with Nitrogen were quite apparent in which wellexfoliated samples were formed as shown in Figure 2(b) [15]. Functioning the exfoliated sheets with the copper salt and further calcined in the $\mathrm{N}_{2} / \mathrm{H}_{2}$ atmosphere had exfoliated the sheet further. The morphology of the $\mathrm{Cu} / \mathrm{N}-\mathrm{rGO}$ nanosheets formed is depicted in 
Figure 2(c). With the dispersion of the 1 wt $\% \mathrm{Cu}$, the compacted shaped of the N-rGO was leavened and formed a lightweight foamlike structure, the findings as in [16].

The TEM image of the GO (Figure 3(a)) shows that each visible GO flake is comprised of few layers of GO sheet stacked laterally. The image of the GO formed revealed thin and wrinkle nanosheets such that it could allow the passage of electron beam [14]. The GO nanosheets also had crumple and ripple structures and in the lateral size ranged from nanometers up to a few micrometers as that described by [17]. The appearance of these features might be due to the deformation of the graphite oxide layers that occurred during the exfoliation and restacking processes.

The modification of the reduced GO with $\mathrm{Ni}$ trogen displayed a corrugated effect on the GO resulting in isolated small fragments on the surface as shown by the TEM image in Figure 3(b) $[18,19]$. This observation is consistent with the formation of multilayer structure as shown by the TEM image in Figure 3(c) [20] which could be attributed to the defect structure formed upon exfoliation and the presence of for-


eign nitrogen atoms [21]. Furthermore, a welldispersed $\mathrm{Cu}$ nanoparticle is noticeable on the surface of N-rGO as presented by TEM images in Figure 3 (d and e) [16]. The particle size distribution revealed that the $\mathrm{Cu}$ nanoparticles were in the range of $5.0 \mathrm{~nm}$ to $50.0 \mathrm{~nm}$ with a mean diameter of $27.5 \mathrm{~nm}$ [22].

\subsection{Energy-Dispersive X-ray Spectroscopy Analysis (EDX)}

The elemental compositions of GO, N-rGO, and $\mathrm{Cu} / \mathrm{N}-\mathrm{rGO}$ catalysts obtained from the EDX analysis are shown in Table 1 and the micrographs of the samples are shown in Figure 4. Interestingly, all components $(\mathrm{C}, \mathrm{O}, \mathrm{N}$, and $\mathrm{Cu}$ ) were found in the proportions of 76.06 wt\%, $14.86 \mathrm{wt} \%, 7.22 \mathrm{wt} \%$, and $1.86 \mathrm{wt} \%$, respectively. The results also confirmed that the oxygen-containing functional groups could be removed during the $\mathrm{N}$-doping process with the ratio $(\mathrm{Cu} / \mathrm{C})$ of 0.024$)[23-25]$.

\subsection{Thermal Gravimetric Analysis}

The TGA profile showing the thermal behavior of the as-prepared GO, N-rGO, and $\mathrm{Cu} / \mathrm{N}-\mathrm{rGO}$ sheets under the temperatureprogrammed calcination environment is depicted in Figure 5. The temperature-programmed calcination was conducted in a flow of nitrogen at a temperature range of $50-900{ }^{\circ} \mathrm{C}$. The GO exhibits more than $80 \%$ weight loss between $100-470{ }^{\circ} \mathrm{C}$ resulting from the removal of the labile oxygen-containing functional groups, such as $\mathrm{CO}, \mathrm{CO}_{2}$, and $\mathrm{H}_{2} \mathrm{O}$ vapors. The N-rGO sheets show much higher thermal stability with mass loss up to $262{ }^{\circ} \mathrm{C}$. The mass loss ob-

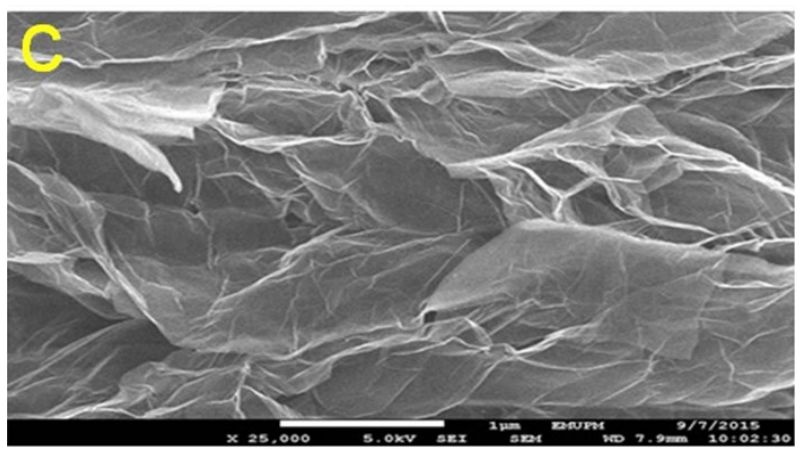

Figure 2. FESEM of (a) GO, (b) N-rGO and (c) Cu/N-rGO.

Table 1. EDX analysis for GO, N-rGO and Cu/N-rGO.

\begin{tabular}{lllcc}
\hline Element & $\mathrm{C}(\%)$ & $\mathrm{O}(\%)$ & $\mathrm{N}(\%)$ & $\mathrm{Cu}(\%)$ \\
\hline GO & 45.67 & 54.33 & 0 & 0 \\
N-rGO & 78.17 & 15.85 & 5.98 & 0 \\
Cu/N-rGO & 76.06 & 14.86 & 7.22 & 1.86 \\
\hline
\end{tabular}




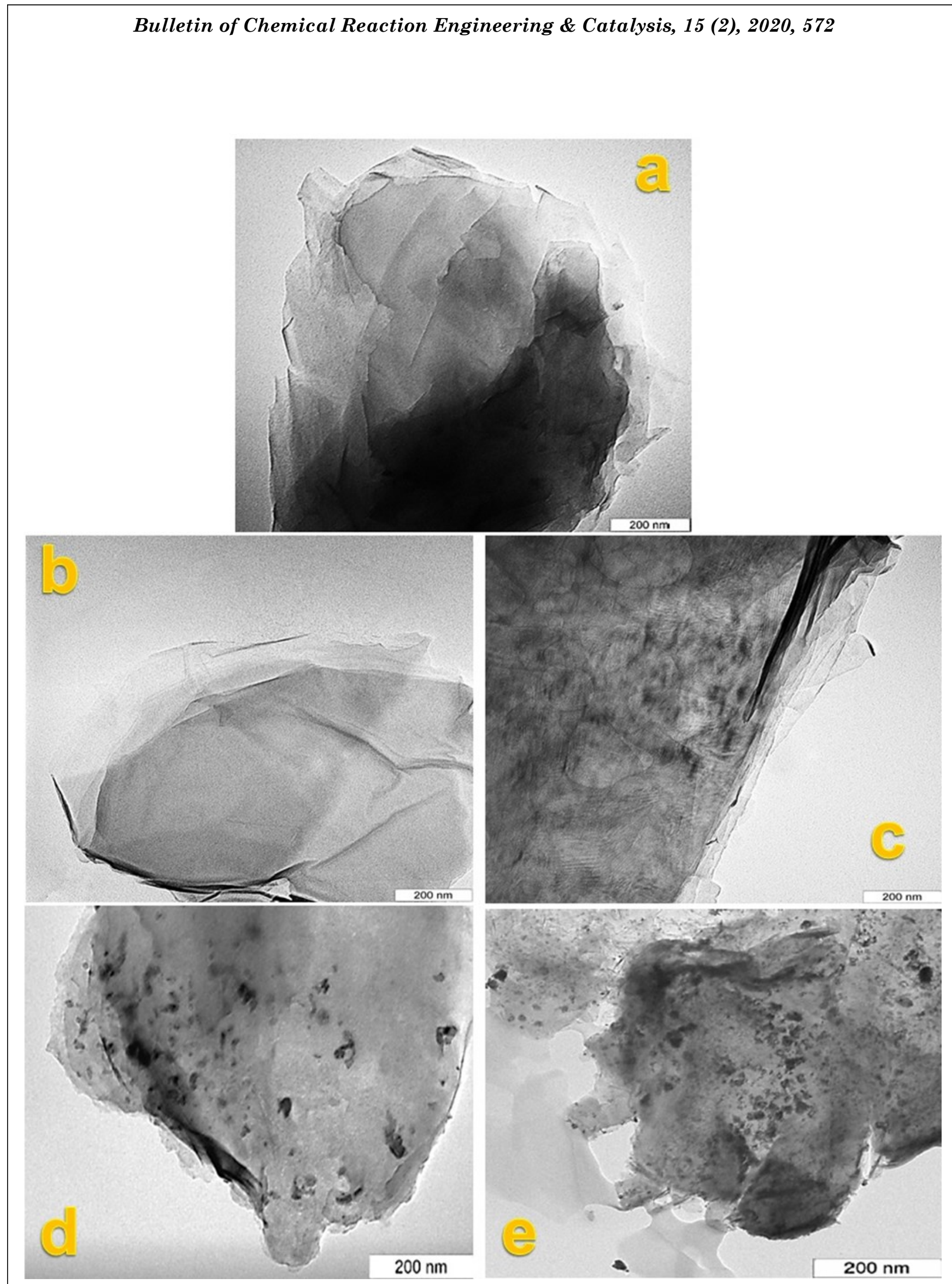

Figure 3. TEM of (a) GO, (b, c) N-rGO and (d, e) Cu/N-rGO. 
served is probably due to the evaporation of the adsorbed water and the presence of such oxygen components [26].

Supporting metal nanoparticles on the graphene sheets could prevent the formation of stacked graphitic structures since the metal nanoparticles can act as spacers to increase the distance between the sheets. This could lead to increasing the surface area of the nanoparticle-


graphene sheets. These materials may have promising potential applications in catalysis [27].

In Figure 5, the weight loss in the range of $150-280^{\circ} \mathrm{C}$ for the $\mathrm{Cu} / \mathrm{N}-\mathrm{rGO}$ can be attributed to the combustion of the carbon skeleton of the graphene. At a temperature $>280{ }^{\circ} \mathrm{C}$, there was no further loss of weight which is an indication that the $\mathrm{Cu} / \mathrm{N}-\mathrm{rGO}$ catalyst is in its pure form. It is obvious that the $\mathrm{Cu} / \mathrm{N}-\mathrm{rGO}$ is more thermally stable compared to GO and N-rGO [28].

\subsection{XRD Analysis}

The XRD pattern of the $\mathrm{Cu} / \mathrm{N}-\mathrm{rGO}$ is depicted in Figure 6. The crystallite of the element identified includes copper $(\mathrm{Cu})$, nitrogen $(\mathrm{N})$, graphite $(\mathrm{C})$, and oxygen $(\mathrm{O})$. The crystallite of the various elements was identified at a $2 \theta$ range of $10-145{ }^{\circ} \mathrm{C}$. The crystallite at $2 \theta=$ $24.84^{\circ}$, and $58.68^{\circ}$ can be attributed to the presence of reduced graphene oxide. At $2 \theta=$ $43.25^{\circ}$, and $61.70^{\circ}$, the crystallite phase repre-

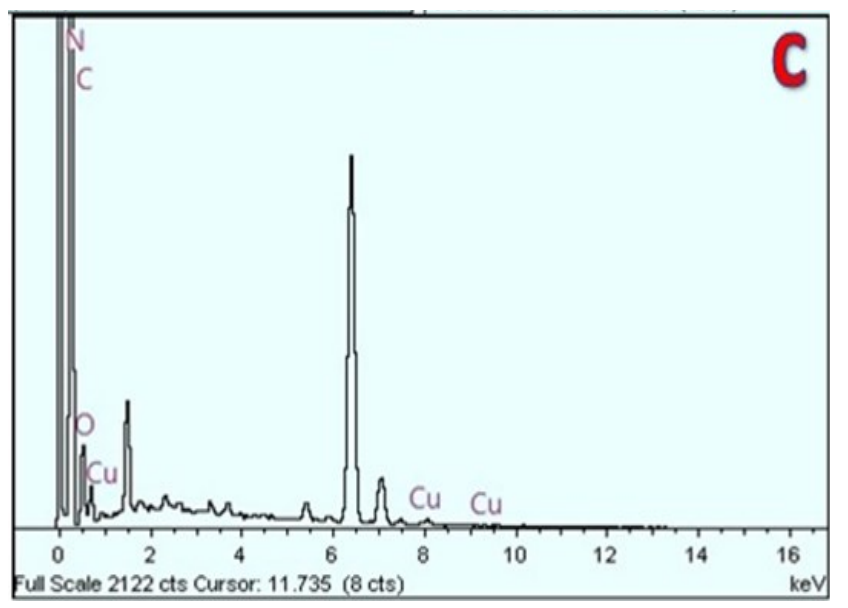

Figure 4. EDX micrograph of the (a) (GO), (b) (N-rGO) and (c) (Cu/N-rGO).

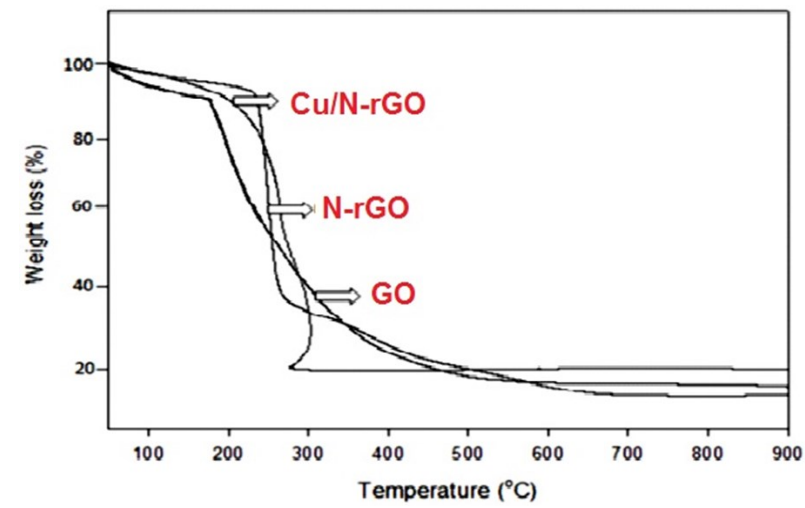

Figure 5. TGA plots for GO, N-RGO, and $\mathrm{Cu} / \mathrm{N}-\mathrm{rGO}$.

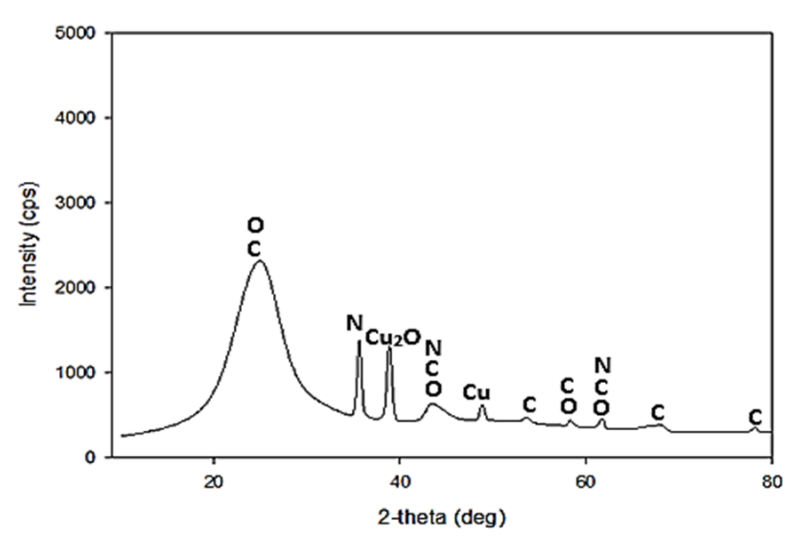

Figure 6. XRD Plots of the $\mathrm{Cu} / \mathrm{N}-\mathrm{rGO}$ catalyst. 
senting the presence of the $\mathrm{N}$-doped graphene oxide can be identified. The identification of copper(II) oxide is evidence at $2 \theta=38.77^{\circ}$ while copper crystallite can be identified at $2 \theta=$ $53.68^{\circ}$. The identification of graphite can be attributed to the peaks $2 \theta=58.11^{\circ}, 68.11^{\circ}$, and $76.1^{\circ}$. It can be seen that the formation of the $\mathrm{Cu} / \mathrm{N}$-rGO catalyst is evident from the XRD pattern which is consistent with that observed using the EDX analysis shown in Figure 4.

\subsection{Raman Spectroscopy}

The Raman spectra analysis of GO, N-rGO, and $\mathrm{Cu} / \mathrm{N}-\mathrm{rGO}$, showing the characteristic of the $D$ and $G$ bands are depicted in Figure 7 . The $\mathrm{D}$ band displayed in the catalysts can be attributed to the defects-induced zone edge phonons while the $\mathrm{G}$ band signifies the doubly degenerate zone center E2g mode [29]. To quantify the defects in the graphene materials, the ratio of the intensity of the $D$ band to $G$ band was estimated for GO, N-rGO, and $\mathrm{Cu} / \mathrm{N}$ rGO as shown in Table 2. The ID/IG ratios of $0.94,1.02$, and 1.04 obtained for the GO, N$\mathrm{rGO}$, and $\mathrm{Cu} / \mathrm{N}-\mathrm{rGO}$, respectively, are con- sistent with that reported in the literature [30]. The ratios are also indications of the presence of some defects and oxygen functional groups in the as-prepared samples. The variation of the ID/IG ratio between GO and N-rGO signifies the increase in the size of $\mathrm{C} \mathrm{sp} 2$ atom clusters as a result of the simultaneous reduction of GO. Interestingly, the $\mathrm{N}$-doping resulted in the shifting of the G band of the rGO [31]. The estimated $G$ peak positions of the as-prepared GO and N-rGO are approximately 1576.05 and $1573.00 \mathrm{~cm}^{-1}$, respectively. Similarly, the variation in the ID/IG ratios of N-rGO and $\mathrm{Cu} / \mathrm{N}$ rGO from 1.02 to 1.04 , respectively, is an indication of the removal of oxygen functionalities. Moreover, the partially ordered crystal structure of graphene as well as the presence of $\mathrm{Cu}$ nanoparticles on the surface of N-rGO contributes to the 3D structure of N-rGO [25].

\subsection{Catalytic Activity}

The catalytic activity of the $\mathrm{Cu} / \mathrm{N}-\mathrm{rGO}$ catalyst in the dehydrogenation of cyclohexanol to cyclohexanone is depicted in Figures 8 and 9. Significantly, there was an increase in the con-
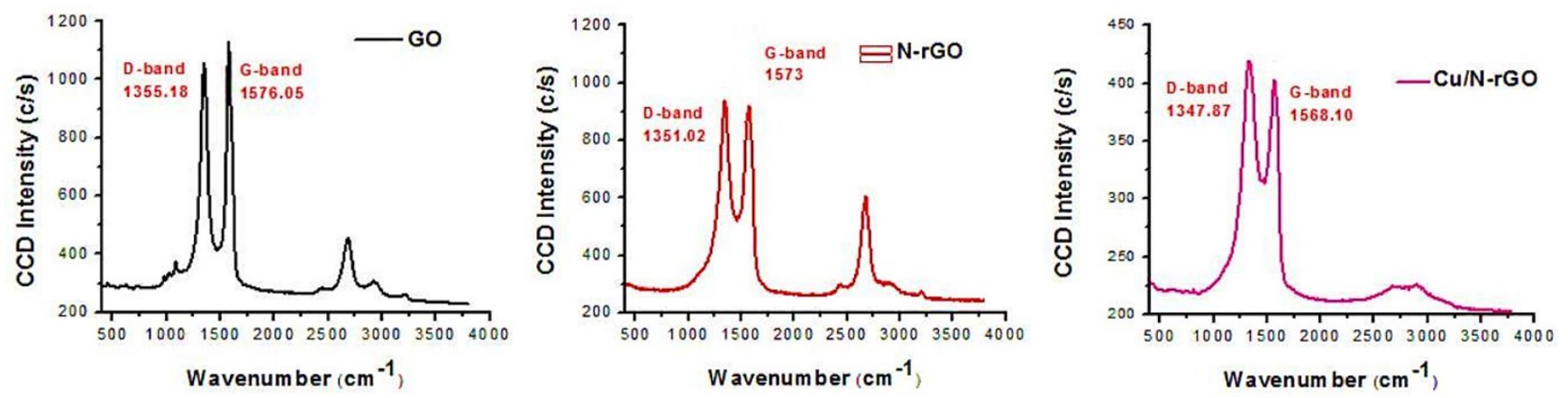

Figure 7. Raman Curves of GO, N-rGO, and $\mathrm{Cu} / \mathrm{N}-\mathrm{rGO}$.
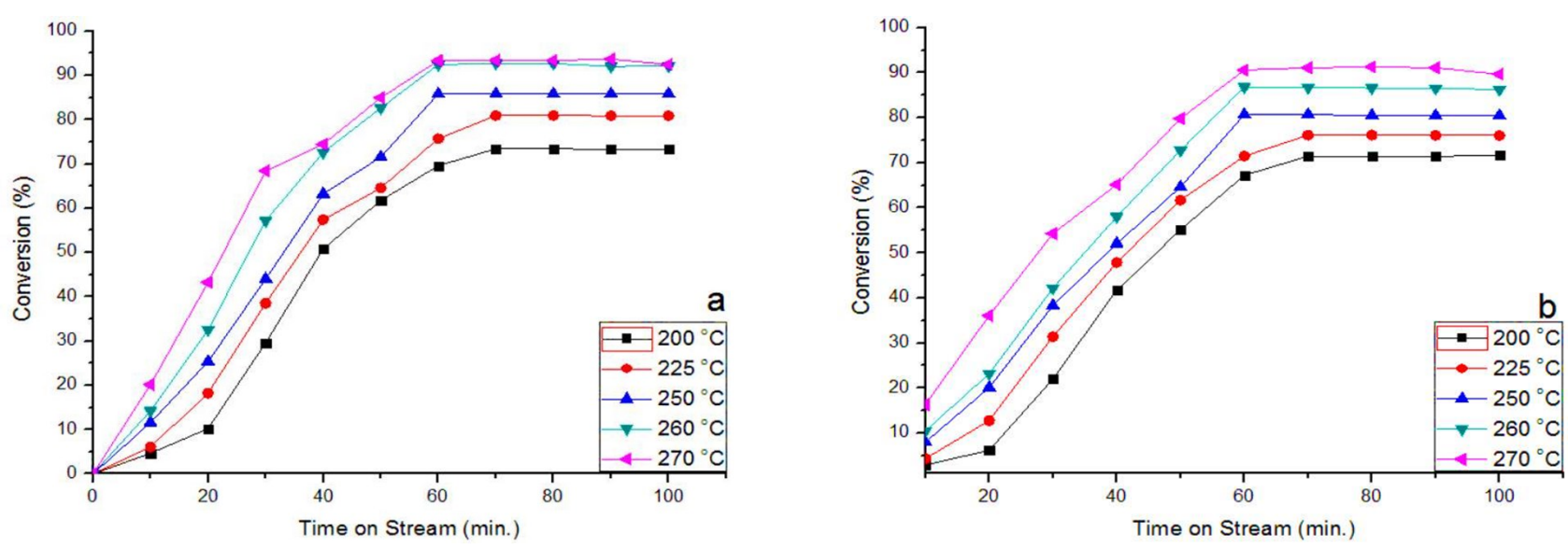

Figure 8. Conversion of cyclohexanol vs. time on stream at different operating temperatures for cyclohexanol flow rates: (a) $0.1 \mathrm{~mL} \cdot \mathrm{min}^{-1}$ and (b) $0.2 \mathrm{~mL} \cdot \mathrm{min}^{-1}$. 
version of cyclohexanol with a rise in temperature which is consistent with Arrhenius's concept for temperature-dependent reactions, such as dehydrogenation [32]. Based on Arrhenius's concept, the activity of a temperaturedependent reaction increases with an increase in temperature. The cyclohexanol conversion increases from $73.42 \%$ at $200{ }^{\circ} \mathrm{C}$ to a maximum value of $93.6 \%$ at $270{ }^{\circ} \mathrm{C}$, consistent with the findings of [33].

The catalytic activity of the $\mathrm{Cu} / \mathrm{N}-\mathrm{rGO}$ catalyst in terms of product yields also increases with temperature climaxing with the highest cyclohexanone yield of $78.3 \%$ at $270{ }^{\circ} \mathrm{C}$ and 0.1 $\mathrm{mL} / \mathrm{min}$. However, the selectivity of cyclohexanone using the $\mathrm{Cu} / \mathrm{N}$-rGO catalyst represented in Figure 9 decreased with a rise in temperatures and flow rates (Table 3 ). This could be at- tributed to the formation of by-products, such as cyclohexene and phenol, resulting from the influence of side reactions and subsequent dehydrogenation of cyclohexanone at elevated temperatures [34]. The improved catalytic activity can be attributed to the excellent physicochemical properties of the catalysts, such as the optimized dispersion and size distribution of $\mathrm{Cu}$ NPs on N-rGO. Moreover, there is a synergistic effect of the Nitrogen dopant due to the exceptional electronic properties which originate from the conjugated lone pair electron of the nitrogen and the reduced graphene oxide [35]. Synergistic effect of nitrogen-doped catalysts has been explored in various catalytic processes, such as: hydrogen evolution reaction [36] and oxygen reduction [37].
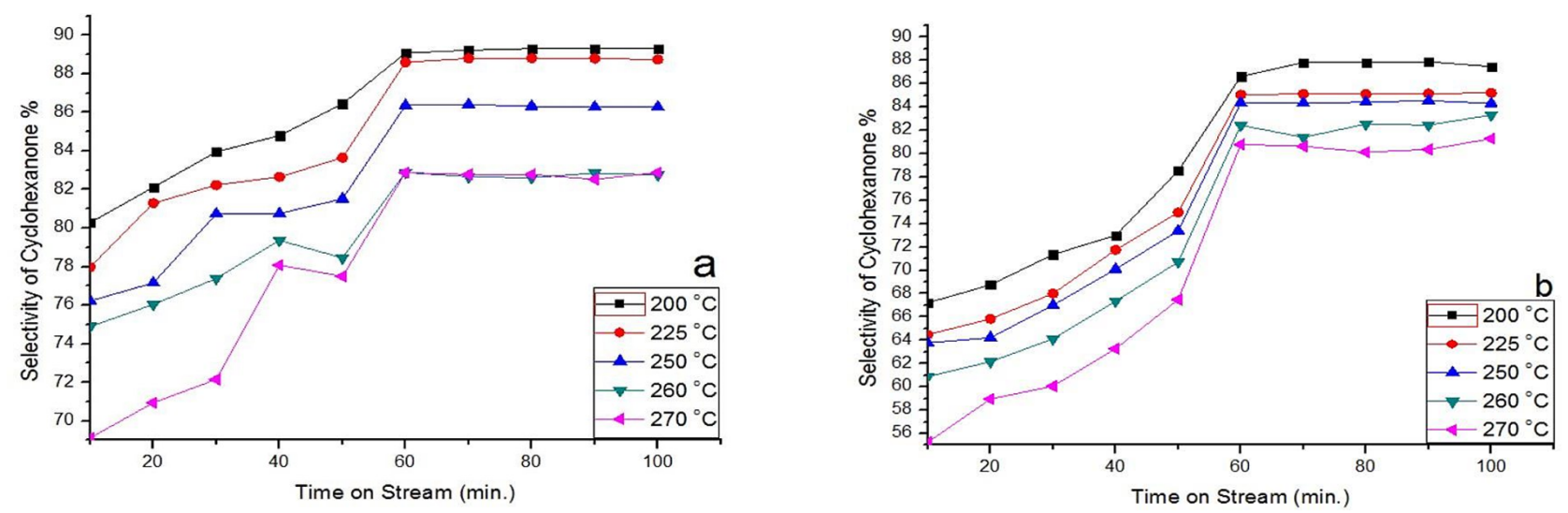

Figure 9. The selectivity of cyclohexanone vs. time on stream at different operating temperatures for cyclohexanol flow rates: (a) $0.1 \mathrm{~mL} \cdot \mathrm{min}^{-1}$ and (b) $0.2 \mathrm{~mL} \cdot \mathrm{min}^{-1}$.

Table 2. Position and intensity of $\mathrm{D}$ and $\mathrm{G}$ bands and ID/IG ratios.

\begin{tabular}{lccccc}
\hline & D position $\left(\mathrm{cm}^{-1}\right)$ & D intensity & G position $\left(\mathrm{cm}^{-1}\right)$ & G intensity & $\mathrm{I}_{\mathrm{D}} / \mathrm{I}_{\mathrm{G}}$ \\
\hline GO & 1355.18 & 1060 & 1576.05 & 1125.86 & 0.94 \\
N-rGO & 1351.02 & 944. & 1573.00 & 926 & 1.02 \\
Cu/N-rGO & 1347.87 & 419.18 & 1568.10 & 402.14 & 1.04 \\
\hline
\end{tabular}

Table 3. Effect of temperature on the activity and selectivity of the $\mathrm{Cu} / \mathrm{N}$-rGO catalyst for cyclohexanol flow rate of $0.1 \mathrm{~mL} \cdot \mathrm{min}^{-1}$.

\begin{tabular}{cccc}
\hline $\begin{array}{c}\text { Temperature } \\
\left({ }^{\circ} \mathrm{C}\right)\end{array}$ & $\begin{array}{c}\text { Conversion } \\
\text { of Cyclohexanol (\%) }\end{array}$ & $\begin{array}{c}\text { Selectivity } \\
\text { of Cyclohexanone (\%) }\end{array}$ & $\begin{array}{c}\text { Yield } \\
\text { of Cyclohexanone (\%) }\end{array}$ \\
\hline 200 & 73.42 & 89.31 & 65.51 \\
225 & 80.95 & 88.81 & 71.88 \\
250 & 85.80 & 86.32 & 74.14 \\
260 & 92.75 & 82.62 & 76.67 \\
270 & 93.39 & 82.78 & 77.01 \\
\hline
\end{tabular}




\section{Conclusions}

This study has investigated the dehydrogenation of cyclohexanol to cyclohexanone over $\mathrm{Cu} / \mathrm{N}-\mathrm{rGO}$ catalyst. In this study, the facile synthesis N-rGO by chemical reduction was demonstrated for the first time. The assynthesized N-rGO was subsequently utilized as a support for the preparation of the $\mathrm{Cu}$ nanoparticles catalyst. The as-prepared $\mathrm{Cu} / \mathrm{N}$ rGO catalyst was characterized and subsequently tested in the dehydrogenation of cyclohexanol to cyclohexanone at a temperature range of $200-270{ }^{\circ} \mathrm{C}$. The FESEM and TEM analysis showed a well-dispersed $\mathrm{Cu}$ NPs with small particle sizes on N-rGO sheets. The catalytic activity of the $\mathrm{Cu}$ NPs supported on NrGO in dehydrogenation reactions showed that the activity in terms of conversions and yields increases with temperature. The highest cyclohexanol conversion as well as the highest cyclohexanone selectivity of $93.3 \%$ and $82.7 \%$ respectively were obtained from using the $\mathrm{Cu} / \mathrm{N}$ rGO catalyst. The improved activity and stability have been attributed to the optimized dispersion and size distribution of $\mathrm{Cu}$ NPs on NrGO making a promising catalyst for the production of cyclohexanone via dehydrogenation of cyclohexanol.

\section{Acknowledgements}

The authors would like to acknowledge the Fundamental Research Grant scheme with the number 03-02-1522FR for making this research possible.

\section{References}

[1] Wang, Z., Liu, X., Rooney, D.W., Hu, P. (2015). Elucidating the mechanism and active site of the cyclohexanol dehydrogenation on copper-based catalysts: A density functional theory study. Surface Science, 640, 1-9.

[2] Fridman, V.Z., Davydov, A.A. (2000). Dehydrogenation of Cyclohexanol on CopperContaining Catalysts I. The Influence of the Oxidation State of Copper on the Activity of Copper Sites. Journal of Catalysis, 195, 2030.

[3] Jeon, G.S., Chung, J.S. (1994). Preparation and characterization of silica-supported copper catalysts for the dehydrogenation of cyclohexanol to cyclohexanone. Applied Catalysis A. General, 115(1), 29-44.

[4] Simón, E., Rosas, J.M., Santos, A., Romero, A. (2012). Study of the deactivation of copperbased catalysts for dehydrogenation of cyclohexanol to cyclohexanone, Catalysis Today, 187(1), 150-158.
[5] Song, Z., Ren, D., Wang, T., Jin, F., Jiang, Q., Huo, Z. (2015). Highly selective hydrothermal production of cyclohexanol from biomassderived cyclohexanone over $\mathrm{Cu}$ powder. $\mathrm{Ca}$ talysis Today, 274, 94-98.

[6] Ranga Rao, G., Meher, S.K., Mishra, B.G., Charan, P.H.K. (2012). Nature and catalytic activity of bimetallic $\mathrm{CuNi}$ particles on $\mathrm{CeO}_{2}$ support. Catalysis Today, 198(1), 140-147.

[7] Chary, K.V.R., Seela, K.K., Naresh, D., Ramakanth, P. (2008). Characterization and reductive amination of cyclohexanol and cyclohexanone over $\mathrm{Cu} / \mathrm{ZrO}_{2}$ catalysts. Catalysis Communications, 9(1), 75-81.

[8] Huízar-Félix, A.M., Cruz-Silva, R., Barandiarán, J.M., García-Gutiérrez, D.I., Orue, I., Merida, D., Sepúlveda-Guzmán, S. (2016). Magnetic properties of thermally reduced graphene oxide decorated with PtNi nanoparticles. Journal of Alloys and Compounds, 678, 541-548.

[9] Yang, J., Shen, X., Ji, Z., Zhou, H., Zhu, G., Chen, K. (2015). In-situ growth of $\mathrm{Cu}$ nanoparticles on reduced graphene oxide nanosheets and their excellent catalytic performance. Ceramics International, 41(3), 4056-4063.

[10] Ma, J., Wang, L., Mu, X., Li, L. (2015). Nitrogen-doped graphene supported Pt nanoparticles with enhanced performance for methanol oxidation. International Journal of Hydrogen Energy, 40(6), 2641-2647.

[11] Fakhri, P., Jaleh, B., Nasrollahzadeh, M. (2014). Synthesis and characterization of copper nanoparticles supported on reduced graphene oxide as a highly active and recyclable catalyst for the synthesis of formamides and primary amines. Journal of Molecular Catalysis A: Chemical, 383-384, 17-22.

[12] Lee, D.W., Seo, J.W. (2011). Preparation of carbon nanotubes from graphite powder at room temperature. arXiv preprint arXiv. 1007, 1-10.

[13] Ning, R., Tian, J., Asiri, A.M., Qusti, A.H., AlYoubi, A.O., Sun, X. (2013). Spinel $\mathrm{CuCo}_{2} \mathrm{O}_{4}$ nanoparticles supported on n-doped reduced graphene oxide: A highly active and stable hybrid electrocatalyst for the oxygen reduction reaction. Langmuir, 29(43), 1314613151.

[14] Loryuenyong, V., Totepvimarn, K., Eimburanapravat, P., Boonchompoo, W., Buasri, A. (2013). Preparation and Characterization of Reduced Graphene Oxide Sheets via WaterBased Exfoliation and Reduction Methods. Advances in Materials Science and Engineering, 2013, 1-6. 
[15] Seung Hun, H., Hae-Mi, J., Sung-Ho, C. (2010). X-ray Diffraction Patterns of Thermally-reduced Graphenes. Journal of the Korean Physical Society, 57(61), 1649-1652.

[16] Ismail, N., Madian, M., El-Shall, M.S. (2015). Reduced graphene oxide doped with $\mathrm{Ni} / \mathrm{Pd}$ nanoparticles for hydrogen storage application. Journal of Industrial and Engineering Chemistry, 30, 328-335.

[17] Fu, C., Zhao, G., Zhang, H., Li, S. (2013). Evaluation and Characterization of Reduced Graphene Oxide Nanosheets as Anode Materials for Lithium-Ion Batteries. International Journal of Electrochemical Sciences, 8, 62696280 .

[18] Stankovich, S., Dikin, D.A., Piner, R.D., Kohlhaas, K.A., Kleinhammes, A., Jia, Y., Wu, Y., Nguyen, S.T., Ruoff, R.S. (2007). Synthesis of graphene-based nanosheets via chemical reduction of exfoliated graphite oxide. Carbon, 45(7), 1558-1565.

[19] Alanyalioglu, M., Segura, J.J., Oro-Sol, J., Casan-Pastor, N. (2012). The synthesis of graphene sheets with controlled thickness and order using surfactant-assisted electrochemical processes. Carbon, 50(1), 142-152.

[20] Zhang, W., Wu, P., Li, Z., Yang, J. (2011). First-principles thermodynamics of graphene growth on $\mathrm{Cu}$ surfaces. Journal of Physical Chemistry C, 115, 17782-17787.

[21] Zhen-Jiang, L., Mao-wen, X., Shu-Juan, B., Kehfarn, T., Hui, C., Chang-Jun, C., ChenChen, J., Qiang, Z. (2013). Facile preparation of nitrogen-doped graphene as a metal-free catalyst for oxygen reduction reaction. $J M a$ ter Sci., 48(10), 8101-8107.

[22] Yang, J., Shen, X., Ji, Z., Zhou, H., Zhu, G., Chen, K. (2015). In-situ growth of $\mathrm{Cu}$ nanoparticles on reduced graphene oxide nanosheets and their excellent catalytic performance. Ceramics International, 41(3), 4056-4063.

[23] Neha, B. (2012). Synthesis and Characterization of Exfoliated Graphite/ABS Composites. Open Journal of Organic Polymer Materials, 02(04), 75-79.

[24] Li, Y., Ye, K. Cheng, K., Cao, D., Pan, Y., Kong, S., Wang, G. (2014). Anchoring CuO nanoparticles on nitrogen-doped reduced graphene oxide nanosheets as electrode material for supercapacitors. Journal of Electroanalytical Chemistry, 727, 154-162.

[25] Jia, Z., Chen, T., Wang, J., Ni, J., Li, H., Shao, X. (2015). Synthesis, characterization and tribological properties of $\mathrm{Cu} /$ reduced graphene oxide composites. Tribology International, 88, 17-24.
[26] Shateesh, B., Markad, G.B., Haram, S.K. (2016) Nitrogen doped Graphene Oxides as an efficient electrocatalyst for the Hydrogen evolution Reaction; Composition based Electrodics Investigation. Electrochemical Acta, 200, 53-58.

[27] Hassan, H.M.A., Abdelsayed, V., Khder, A.E.R.S., AbouZeid, K.M., Terner, J., ElShall, M.S., Al-Resayes, S.I., El-Azhary A.A. (2009). Microwave synthesis of graphene sheets supporting metal nanocrystals in aqueous and organic media. Journal of Materials Chemistry, 19(23), 3832-3837.

[28] Ding, T., Tian, H., Liu, J., Wu, W., Zhao, B. (2016). Effect of promoters on hydrogenation of diethyl malonate to 1,3-propanediol over nano copper-based catalysts. CATCOM, 74, 10-15.

[29] Shahriary, L., Athawale, A.A. (2014). Graphene Oxide Synthesized by using Modified Hummers Approach. International Journal of Renewable Energy and Environmental Engineering, 02(01), 58-63.

[30] Shao, G., Lu, Y., Wu, F., Yang, C., Zeng, F., Wu, Q. (2012). Graphene oxide: The mechanisms of oxidation and exfoliation. Journal of Materials Science, 47(10), 4400-4409.

[31] He, D., Jiang, Y., Lv, H., Pan, M., Mu, S. (2013). Nitrogen-doped reduced graphene oxide supports for noble metal catalysts with greatly enhanced activity and stability. $A p$ plied Catalysis B: Environmental, 132-133, 379-388.

[32] Ayodele, B.V., Hossain, M.A., Chong, S.L., Soh, J.C., Abdullah, S., Khan, M.R., Cheng, C.K. (2016). Non-isothermal kinetics and mechanistic study of thermal decomposition of light rare earth metal nitrate hydrates using thermogravimetric analysis. Journal of Thermal Analysis and Calorimetry, 125(1), 423-435.

[33] Popova, M., Dimitrov, M., Santo, V.D., Ravasio, N., Scotti, N. (2012). Dehydrogenation of cyclohexanol on copper containing catalysts: The role of the support and the preparation method. Catalysis Communications, 17, 150-153.

[34] Simon, E., Pardo, F., Lorenzo, D., Santos, A., Romero, A. (2012). Kinetic model of 2cyclohexenone formation from cyclohexanol and 2-cyclohexenol dehydrogenation. Chemical Engineering Journal, 192, 129-137.

[35] Li, M., Zhang, L., Xu, Q., Niu, J., Xia, Z. (2014). N-doped graphene as catalysts for oxygen reduction and oxygen evolution reactions: Theoretical considerations. Journal of catalysis, 314, 66-72. 
[36] Li, D.J., Maiti, U.N., Lim, J., Choi, D.S., Lee, W.J., Oh, Y., Song, H., Zhong, Y., Kim, S.O. (2014). Molybdenum sulfide/N-doped CNT forest hybrid catalysts for high-performance hydrogen evolution reaction. Nano letters, 14(3), 1228-1233.
[37] Peng, H., Mo, Z., Liao, S., Liang, H., Yang, L., Luo, F., Song, H., Zhong, Y., Zhang, B. (2013). High performance $\mathrm{Fe}$-and $\mathrm{N}$-doped carbon catalyst with graphene structure for oxygen reduction. Scientific Reports, 3, 1-7. 